\title{
Inventing the randomized double-blind trial: the Nuremberg salt test of 1835
}

\author{
M Stolberg
}

J R Soc Med 2006;99:642-643

Additional material for this article is available from the James Lind Library website [http://www.jameslindlibrary.org], where this paper was previously published.

Control groups, randomization, blinding, placebos and related methods designed to eliminate bias have become widely recognized as key features of efforts to identify more effective and safer treatments. As others have shown, ${ }^{1,2}$ many of these methods were first developed and applied in the context of controversies between mainstream medicine and new, 'alternative' types of medicine. A very early example of randomization and double blinding was an evaluation of homeopathy conducted in Nuremberg in 1835 by a 'society of truth-loving men.' $3-5$

At the time, homeopathy had garnered considerable support among the upper classes in the then Kingdom of Bavaria. In Nuremberg, one of Bavaria's largest and most affluent cities, Karl Preu and Johann Jacob Reuter had treated some of the most prominent families with homeopathy, including members of the high aristocracy. In 1834, annoyed by homeopathy's rising popularity, Friedrich Wilhelm von Hoven, the city's highest ranking public health official and head of the local hospitals, published a devastating critique of homeopathy under the pseudonym 'E_.F_.Wahrhold', ${ }^{6}$ which he had used previously in a way that allowed readers to identify the true author. Von Hoven accused homeopathy of lacking any scientific foundation. He suggested that homeopathic drugs were not real medicines at all and alleged homeopathic cures were either due to dietetic regimens and the healing powers of nature, or showed the power of belief. He called for an objective, comparative assessment by impartial experts. If, as he expected, homeopathic treatment proved ineffective, the government would need to take drastic measures to protect the lives of deceived patients.

In 1835, by which time Karl Preu had died, Johann Jacob Reuter was the sole remaining physician homeopath in the city. He reacted to Wahrhold/von Hoven's attack with an ardent defence of homeopathy ${ }^{7}$ and pointed out that

Institut für Geschichte der Medizin, Oberer Neubergweg 10a, 97074 Würzburg,

Germany

642
E-mail: michael.stolberg@mail.uni-wuerzburg.de even children, lunatics and animals had been successfully cured. Based on Hahnemann's assertions, he challenged Wahrhold/von Hoven to try the effects of a C30 dilution of salt on himself. The odds were ten to one, he claimed, that his opponent would experience some extraordinary sensations as a result - and these were nothing compared to the much stronger effects on the sick.

Perhaps surprisingly, Reuter's opponents took up his challenge. Various (allopathic) pharmacists and physicians conducted individual tests, following Reuter's indications. Then it was decided to stage a larger-scale trial. It remains uncertain who took the initiative for this, but it was probably von Hoven and the circle of physicians around him. They were supported by George Löhner, the owner and editor of the daily Allgemeine Zeitung von und für Bayern, who later compiled the trial report. Löhner had no medical training but his newspaper had repeatedly carried polemical attacks against homeopathy.

Following a widely publicized invitation to anyone who was interested, more than 120 citizens met in a local tavern. The minimum number needed to proceed had been fixed at 50. The design of the proposed trial was explained in detail. In front of everyone, 100 vials were numbered, thoroughly shuffled and then split up at random into two lots of 50. One lot was filled with distilled snow water, the other with ordinary salt in a homeopathic C30-dilution of distilled snow water, prepared just as Reuter had demanded: a grain of salt was dissolved in 100 drops of distilled snow water and the resulting solution was diluted 29 times at a ratio of 1 to 100 . Great care was taken to avoid any contamination with allopathic drugs. The two pharmacists in charge had taken two days off before the experiment. They had taken a bath and they used new weighing scales which had not even come close to an allopathic pharmacy.

A list indicating the numbers of the vials with and without the salt dilution, respectively, was made and sealed. The vials were then passed on to a 'commission' which distributed 47 of the vials to those among the audience who had declared their willingness to participate (the report speaks of 48 vials but this included an unnumbered vial with salt dilution given to a physician by the name of Lochner). The participants' names and the number of the vial that each had received were written in a second list. Seven more 
numbered vials were distributed after the meeting by one of the members of the commission.

Three weeks later, at a second meeting, the participants were asked to report whether they had experienced anything unusual after ingesting the vial's content. Those who did not come to the meeting were asked to send this information in. Responses were thus obtained from 50 of the 54 participants. Those participants who had perceived something unusual described their symptoms, as required by the protocol.

Finally, the sealed lists were opened to see who had received water and who the homeopathic dilution, and a list of results was compiled. It turned out that only eight out of the 50 participants who reported back had experienced anything unusual. Five of them had received the dilution, three had received water (somewhat confusingly, the report mentions Dr Löhner as a 51 st reporting participant and the 9th who had experienced symptoms; but he was aware that he had taken the salt dilution and thus had not actually participated in the trial). The vast majority of those who had received the homeopathic salt dilution had thus not experienced any 'effect'. The investigators concluded that Reuter was wrong.

From a modern point of view, the major features of the trial can be summarized as follows:

(1) The trial design (protocol) was carefully set out and the details of the study were made public in advance;

(2) The number of participants was relatively large and the differences between the two groups would have been significant if Reuter had been right;

(3) Assignment to one group or the other was apparently perfectly randomized;

(4) A control group receiving only placebo was used;

(5) The trial was double blind: neither the participants nor those who organized the trial, distributed the vials and documented the effects had any idea whether a vial contained the homeopathic high dilution or merely water;

(6) A rough comparative statistics of the results was compiled;

(7) Irregularities were carefully recorded, such as the failure of four participants to report back, and the fact that several vials were distributed only after the first tavern meeting.
The organizers concluded that the symptoms or changes which the homeopaths claimed to observe as an effect of their medicines were the fruit of imagination, self-deception and preconceived opinion - if not fraud. In spite of their efforts to achieve perfect blinding and randomization, they seem to have been aware, however, that the homeopaths could come up with solid methodological reasons for not accepting this interpretation: in this specific setting, even randomization and double blinding could not eliminate bias. Most participants seem to have opposed homeopathy, and if they wanted to discredit it, they could do so simply by reporting that they had not experienced anything unusual. No matter whether they actually had received the dilution or not, this would invalidate Reuter's claims. Only if the participants were, in principle, convinced that the substance might have an effect would this problem have been overcome and double blinding could have served its intended purpose.

Historically, the value of the trial report thus lies above all in the principles it set out. The organizers called on others and, in particular, on the homeopaths themselves, to perform and repeat similar trials, with different dilutions, and to make the results public. They stressed once more the punctum saliens, the crucial element of their design: one must avoid anything that might enable the participants and those responsible for the trial to guess whether the actual medicine was given or not.

\section{REFERENCES}

1 Kaptchuk TJ. Intentional ignorance: a history of blind assessment and placebo controls in medicine. Bull Hist Med 1998;72:389-433

2 Dean ME. The Trials of Homeopathy. Origins, Structure and Development. Essen, Germany: KVC Verlag, 2004

3 Stolberg M. Die Homöopathie auf dem Prüfstein. Der erste Doppelblindversuch der Medizingeschichte im Jahr 1835. Münchener medizinische Wochenschrift 1996;138:364-6

4 Stolberg M. Die Homöopathie im Königreich Bayern (1800-1914). Heidelberg: Haug, 1999

5 Löhner G, on behalf of a society of truth-loving men. Die homöopathischen Kochsalzversuche zu Nürnberg [The homeopathic salt trials in Nuremberg]. Nuremberg, 1835

6 Wahrhold EF. Auch Etwas über die Homöopathie. Nuremberg, 1834

7 Reuter JJ. Sendschreiben an Dr E Fr Wahrhold als Erwiederung auf dessen Schrift 'Auch etwas über die Homöopathie'. Nuremberg, 1835 